\title{
Adults living with Type 1 diabetes experienced transformation as an evolving process of responding to illness related challenges and as an outcome of a differentiation of self and body
}

Paterson B, Thorne S, Crawford J, et al. Living with diabetes as a transformational experience. Qual Health Res 1999

Nov;9:786-802.

QUESTION: How and why does the phenomenon of transformation occur in the lives of people with Type 1 diabetes?

\section{Design}

Emergent design based on grounded theory.

\section{Setting}

British Columbia, Canada.

\section{Participants}

22 people (age range $24-81$ y, $64 \%$ women, all white) who were $\geqslant 18$ years of age, had Type 1 diabetes for $\geqslant 15$ years, spoke English, and lived in British Columbia. All participants were competent in diabetes self care management and had good glycaemic control.

\section{Methods}

Data were collected over 2 years. For 3 one week periods, participants recorded decisions they made about diabetes related issues (eg, insulin, skin care) as they were made, using handheld, voice activated tape recorders. Participants were also interviewed at recruitment and within 1 week of each think-aloud recording session (total of four 2 hour interviews). Finally, 2 hour focus groups of 5-8 participants were held to share the findings and to verify the researchers' interpretations.

\section{Main findings}

Participants defined transformation as "“a profound new awareness of what you could be'... in an ongoing series of steps leading toward 'coming to terms with me as a diabetic and me as the person I wish to be"' (p791). Transformation was an ongoing, non-linear process of preserving and renegotiating the balance between themselves and their diseased bodies, which began with the discovery that the individual (not the professional) was the expert in diabetes.

The authors developed a model of transformation in chronic illness in which the transformative experience was portrayed in terms of embracing the challenge that led to transformation and a differentiation of self that led to further transformation. Challenges arose in 2 ways: as a threat to self integrity and as a challenge from others. A threat to self integrity occurred when a person encountered a situation that threatened the desired balance between the self as a person with diabetes and the self as a person who wished to live a normal life (eg, unanticipated hypoglycaemia). Some participants responded to challenges presented by others (eg, a healthcare provider coached 5 participants to consider different ways of doing things).

Transformation was also an outcome of differentiation of self and body. For an illness related problem to be viewed as a challenge rather than a threat, the person had to believe that the disease and its impact could be controlled-this was accomplished by differentiation of self, which involved being beside oneself, watching and reflecting on the self and its experiences. It was an attempt to create an illness experience that was independent of the self, while at same time related to it. Participants often described a new appreciation for their expertise as managers of diabetes and their reluctance to comply with general regimens prescribed by providers. Participants saw transformation as a double edged sword, feeling both autonomous and liberated, and alone and solely responsible for the management of the illness.

\section{Conclusion}

Adults with Type 1 diabetes described transformation as an evolutionary process of responding to illness related challenges and, in doing so, developing a transformed self that was differentiated from the body and the illness.

\section{Source of funding: British Columbia Health Research Foundation. \\ For correspondence: Dr B Paterson, School of Nursing, University of British Columbia, 2211 Wesbrook Mall, Vancouver, British Columbia V6T 2B5, Canada.Fax +1604 8227466.}

\section{COMMENTARY}

Through their research, Paterson et al articulate a rich description of transformation that is congruent with findings of qualitative studies on other chronic illnesses and is a process similar to transformational learning in the educational literature. ${ }^{1}$ Not all researchers have viewed objectification of the body (separation of self from chronic illness) as part of the transformation. For example, some have described a process of integration of the diabetic and personal selves in some individuals with Type 1 and Type 2 diabetes. $^{2}$

Major strengths of the research include the use of multiple data sources, a prolonged period of engagement with participants, and data analysis with the constant comparative method. Participants in this study were highly self directed managers of their own care; not all clients may feel as confident about their expertise nor desire this degree of autonomy. The authors' model of transformation provides a concrete depiction of transformation, but this linear model is somewhat incongruent with the non-linear description and the identification of transformation as a product of the 2 processes of "embracing a challenge" and "differentiation of the self" from the body. Nevertheless, generation of this model is an important step forward, and additional research will refine it.

Clinical applications are many. Recognition that the transformed person is the expert challenges the relevance of the medical model of adherence. Further research is needed to identify alternative models of care. The participants' complaints of feeling alone and solely responsible as autonomous experts is of concern, particularly in diabetes, where close contact with the healthcare team is essential for the ongoing dialogue and assessment required for prevention, early detection, and treatment of debilitating complications. Interventions that relate to clients as experiential experts should be developed and tested.

Cheri Ann Hernandez, RN, PhD, CDE Assistant Professor, School of Nursing University of Windsor Windsor, Ontario, Canada

1 Mezirow and Associates. Fostering critical reflection in adulthood: a guide to transformative and emancipatory learning. San Francisco: Jossey Bass, 1990.

2 Hernandez CA, Antone I, Cornelius I.J Transcult Nurs 1999;10:220-8. 